\title{
The Reasons Why Women Do Not Participate in the Pap Smear Screening and Testing Program in Sweden
}

\author{
Annsofie Adolfsson, Karin Granevik, Kerstin Paulson \\ School of Life Sciences, University of Skovde, Skovde, Sweden \\ Email: annsofie.adolfsson@his.se
}

Received May 22, 2012; revised June 27, 2012; accepted July 10, 2012

\begin{abstract}
Cervical cancer is the second most common type of cancer among women worldwide. In Sweden cervical cancer is the fifteenth most common cancer among women and accounts for 1.9 percent of all female cancers. The Swedish Pap smear screening program is enabling early detection of cell changes in order that treatment may be administered to prevent the development of cancerous cells. There are approximately four hundred and fifty cases of cervical cancer detected each year in Sweden and of these cases, approximately seventy five percent occur in women who do not participate in the screening and testing program. The purpose of this study was to illustrate and examine the reasons why women did not participate in the program even though they had received a notice that they had an appointment for a Pap smear test. In the study fourteen women from a district in the west of Sweden were interviewed. In order to analyse the interviews a qualitative content analysis according to Lundman and Graneheim was used. The analysis resulted in the development of three categories which were identified as communication, treatment and subterfuge (reasons or excuses for not participating). The theme of the study was the professional treatment of the women's conditions. In the interviews the women emphasize the importance of professional treatment that is administered with respectful and sympathetic care throughout the whole healthcare system regardless of where and when the visit was conducted. Efficient organization and clear communication would minimize the inconvenience for the women during their visit.
\end{abstract}

Keywords: Attitude; Communication; Pap Smear; Screening; Subterfuge; Women’s Health

\section{Introduction}

Maternity health care in Sweden includes regular Pap smear screening and testing for all women. The par smear test is performed to determine if a woman is healthy or if there are changing cells present or precancerous conditions which are fully diagnosed by a complete examination [1]. Approximately 800,000 Pap smear tests are performed each year in Sweden. The Pap smear testing has been determined to be cost effective by countries Social Services [2]. The testing is performed every three years on women between the age of twenty-three and fifty and every five years on women between the age of fifty and sixty [3]. Cells changing to precancerous cells are a relatively slow process and the process does not present external verifiable symptoms [4].

Testing was introduced in the 1960s but no studies were conducted before the testing began. Since the 1970s cervical cancer in Sweden has been reduced fifty percent to approximately four hundred and fifty diagnosed cases in 2006 of which one hundred twenty-five resulted in terminal cases [2]. Unfortunately the terminal cases probably had a good chance of surviving their illness if it had been detected early enough. But the most common factor determined among these cases was that the women did not participate in the Pap smear testing and screening program. Cervical cancer ranks globally as the most common type of cancer women are diagnosed with but in Sweden cervical cancer ranks only fifteenth as the most common type of cancer diagnosed in women [5]. The risk of being diagnosed with cervical cancer among the women who do not participate in the Pap smear testing and screening program is $2 \%$ compared to $0.5 \%$ for the total population of women $[6,7]$.

The most common cause for cells to change to precancerous states is the virus Human Papilloma virus (HPV) which is transmitted sexually. This condition is much more common among younger sexually active groups and the condition itself does not necessarily require medical treatment because the body usually treats itself back to a healthy state [7]. When called for screening and testing some women may feel uncomfortable or potentially threatened by the procedure and the performance of the test [8]. Since the examination and testing is directly connected to the reproductive system it can be a very sensitive and an emotional experience for a woman. Previous negative experiences in a women's repro- 
ductive and sexual life can contribute to the sensitive nature of the testing process $[9,10]$.

Freedom from illness and sickness is not necessarily the singular primary condition of complete physical, psychological and societal health and wellbeing. From a purely medical perspective health may be defined as absence of illness but a larger view of the total health of a person includes the different perspectives of physical, mental, social and spiritual [11]. Health is not only the actual conditions that are present in the body but also about how the person interprets and experiences these conditions. Two people with the exact same conditions may have an entirely different interpretation of their condition [11].

The Jewish professor Aaron Antonovsky has developed the concept of interpreting health as "salutogena perspective" which according to his theory focuses more on what the reasons are for health than what the reasons are for illness. Antonovsky theorizes that health can be seen as a continuum, with the polar extremities of health and sickness as the outer points. It is between these two points that people exist in a mixed state of health and illness, never completely one or the other. Antonovsky expresses his concept of health with the premise that if an individual has a greater sense and understanding with regards to their own existence it will have a positive influence on their placement in the health continuum. Making sense of where one stands on the health continuum is largely dependent on three components which are understanding, managing and deriving meaningfulness [12].

The aim of this study was to illustrate and examine the reasons why women did not participate in the program even though they had received a notice that they had an appointment for a Pap smear test.

\section{Method}

In this study a qualitative content analysis was performed with an inductive approach according to Graneheim and Lundman [3]. The qualitative method is subjective and the interpretation comes from many realities which are then compared to the theory. The interviews are particularily suitable to describe the women's life experiences [13]. The text that is analyzed must be taken in context. The interviewer was a part of the process and needed to be sensitive to the aspect of nearness and distance of the interviewees with respect to their life experience [14].

\subsection{Data Collection}

The inclusion criteria included three factors. First, the women must have gotten an invitation to get a Pap smear test. Secondly, the women must be able to speak Swedish. The last criterion was that the women had not previously had a diagnosis of changing cells in the cervix. The single exclusion criterion was that the women could not have been treated by the interviewer midwife at any time prior to the interview. Information and invitations to participate in the study were sent to sixty-four potential participants who fell equally into four different age groups, from twenty-three to twenty-nine, from thirty to thirtynine, from forty to forty-nine and from fifty to sixty years of age. Before the interview the participants were given both oral and written information about the aim of the study and they were informed that their participation was voluntary and that they could terminate their participation at any time during the study. Before the study could go forward written approval was obtained from the head of the healthcare center.

The data collection for the study was collected from the interviews with the fourteen participants who volunteered and met the criteria. Each interview consisted of eight semi-structured questions that are listed below and were tape recorded. The interviews lasted between twenty and forty-five minutes in length. The objective of each interview was to be clear, structured and to sensitively listen to what and how the women's experience was expressed in order to make a dynamic conversational interview [13]. The women did not know the nature of the questions prior to the interview in order to insure spontaneous answers. Questions: What feelings did the Pap smear test provoke in you?; How do you think your notification for a Pap smear test was generated and how do you feel about that?; How did you feel about the actual notification itself?; How do you feel about being notified for Pap smear testing every three years?; Can you recall previous gynecology examinations of any nature and describe them?; Why did you choose not to participate in the Pap smear screening and testing program?; With regards to the testing and results how would like the following aspects of the program to be handled when it comes to: Information, Treatment, Testing, Results; How can the care provider improve treatment and increase understanding for women with different experiences and needs?

The interview was concluded after the women had the chance to express their own point of view about Pap smear screening and testing process regarding issues that had not been previously discussed.

\subsection{Data Analysis}

Each interview was transcribed by a secretary who had experience in transcribing interviews. The researchers read and listened to the transcripts and the interviews numerous times together in order to clarify any misunderstandings or answer questions regarding the content and meaning of the interviewees answers and responses. Meaning bearing units were identified and marked with 
different colored markers in order to identify and group the interviewees responses that had similar meanings or identify different expressions of their experiences. In this manner the interview was condensed and easier to manage without losing important aspects of the content [14]. The meaning bearing units made it easier to compare and evaluate the responses in the interviews (Table 1). The result of this coding of meaning bearing units was three main categories and nine subcategories.

\subsection{Ethical Considerations}

All of the transcripts and other materials used for the study were kept securely under lock and key during the studies working period and were destroyed upon completion and approval of the study. A significant benefit of the study was to meet the patient group of women who were reluctant to participate in the screening and testing program. This patient group helped to identify and analyze the issues that women had a hard time working through and discouraged them from participating in the program. In this manner the participation in the program could be increased which would increase the likelihood of finding cell changes in the cervix thereby reducing the risk for cervical cancer.

Risks that may be a by product of this study include the actualization of unresolved emotional issues among the participants regarding past uncomfortable experiences or stirring up bad memories. The researchers secured support before the study for the women who may be in need of therapy with regard to their unresolved issues. For the security of the participants it was confirmed that there was no previous connection between the interviewer and the interviewee in terms of possible caregiver/patient relationships in the past.

\section{Findings}

\subsection{Communication}

The women in the program who did not have a reason to not come to the testing program felt that it was a good idea to get an automatic notification because it served as a reminder to come to the testing program. It actually increased the chances in some cases that the women would respond and take the test. Others decided not to respond to the invitation because they were unsure if they were actually supposed to be tested or not. The invitation comes in the form of a piece of paper that has information on both sides of the paper and the women explained that they often only read the front side of the paper. The form of the notice for the Pap smear screening and testing program was perceived to be informative but also rather strict in the sense that it was tedious and drab according to the women. The women expressed that it was especially important for the women who were being notified for the first time to have more comprehensive information in order to motivate those women to respond and participate in the program.

During the ensuing interview process the interviewer, who is usually a midwife, reveals that the women have missed important information on the back side of the invitation which clearly states that the women should come to the clinic for Pap smear testing because there are no external symptoms of changing cells in the cervix.

Backside? Yeah, maybe I did not turn the page.

The women who participated in the interview process generally had a clear understanding about the testing program and why it was necessary. There were many points made in the interviews that made it clear the women understood that it was a preventative test to detect changing cells in the cervix. Some women were under the incorrect impression that the test was a device to detect cancer. Some women had a limited understanding of their own anatomy. For instance, some did not differentiate between the uterus and the cervix. They knew that the test would be conducted through the vagina but were not exactly clear about what parts of their body were being tested.

The actual procedure for the Pap smear test was unclear given the information provided in the program no-

Table 1. Overview of the domain, sub-categories, categories and theme, from the data of fourteen interviews with women who chose not to participate in the Pap smear program.

\begin{tabular}{lll}
\hline Domain & Subcategory & Category \\
\hline & Lack of knowledge & \\
& Women's different need of information & Communication \\
& Problem with communication & \\
& Responding in kind from various meetings & \\
Women's experience before- & The place & Treatment \\
by pap smear test & Sampling situation arouses feelings & \\
& Violation & Professional treatment of \\
& Priorities & Subterfuge \\
\hline
\end{tabular}


tice and the women felt that it would be beneficial if the information about the actual test was more detailed. The procedure is performed with a wooden spatula and a brush. Cells for testing can be secured in this manner. Some women were under the impression that a biopsy was required for the Pap smear test. The information in the notification maintained that the actual procedure was pain free but some of the women felt that the experience was subjective and felt that there was some pain and discomfort involved in the test.

In the notice it said that it was not painful but there was some physical discomfort involved.

Another concern regarding the information contained in the notification was from women who had previously had other unrelated gynecological procedures who were not sure if the testing notice applied to them. Perhaps they had been given information after the previous procedure and because they were not feeling well at the time they were not able to process that information. Therefore, they were confused by receiving the notification of the Pap smear test.

Generally speaking there seemed to be an excessive amount of misunderstanding that was generated by and not clarified by the notice. It seemed that the information or sometimes the lack of information was confusing to some of the women that were being notified to have the test done.

\subsection{Treatment}

Each of the interviewees discussed the treatment and the importance of the attitude of the caregivers towards them. It was important to the women participating in the testing and screening program that they were treated with dignity and respect. Several of the women felt that they had experienced situations in the healthcare system that had not lived up to their expectations in this regard. Perhaps they had been in a situation where someone in the healthcare system had offended them with an insensitive comment or even a perceived negative facial expression. Perceptions of this type of attitude among the healthcare givers had an influence on the decision for the women to accept or reject the notification for the Pap smear program as they were afraid or intimidated by this sort of behavior.

While being examined it seemed to me that the doctor made a strange expression while examining me in the gynecology chair.

Much of the perceptions and perhaps misperceptions between the caregiver and the patients with respect to gynecology examinations and gynecology care may be attributed to lack of familiarity and trust between the caregiver and the patient. In Sweden the healthcare system is largely a public healthcare system where personnel are constantly changing and perhaps unfortunately the patients do not have the level of trust that is needed for such a sensitive relationship. Because of the lack of familiarity with each other and the intimate nature of the gynecology care, women often did not feel that they had been listened to attentively and they were concerned that their problems had not been totally resolved.

Perceptions of the overall care in the system sometimes were reflected in the women's comments that they felt there was a general lack of comfort in the waiting rooms and examination rooms as well as a lack of comfort with the attitudes and stress levels of the personnel. The women interviewees described different situations where the stress of the personnel influenced their examinations. Some of the women chose to bypass the public healthcare system and instead chose a private facility where they felt that their emotional needs were more effectively met. By switching to the private facility they felt that there was more continuity in the care, more privacy and more intimacy with the caregiver and generally they felt that there was a better bond of trust between the caregiver and the women.

The women were very clear about how they felt the conditions should be in the gynecology examination. The examination room should be calm and secure to the point of calming colors on the walls and suitable calming music in the system. Even the organization and layout of the examination room was important so that the women feel comfortable undressing for the exam and having a proper dressing gown to wear to the examination chair. The position of the chair is important in the sense that there is a maximum sense of privacy for the patient. It is ultimately important the women have a sense of trust with the caregiver and they should not feel hurried through any explanations necessary during the examination. Women often felt that it was appropriate to discuss questions about their sexual behavior, reproductive health and menopause.

It is the overall perception of my experience in this intimate and delicate situation which decides whether or not that I will return.

Beyond the immediate boundaries of the healthcare system in its entirety, a significant number of the women had experienced some form of psychological or sexual abuse in their past. Sometimes these experiences had an influence on the women that made it difficult or uncomfortable for them to respond to the Pap smear screening and testing program because of the negative feelings that were aroused by the testing in their reproductive system.

\subsection{Subterfuge}

Just because a woman does not show up for the Pap smear screening and testing program it does not necessarily imply that she made a conscious decision to reject the program out of hand. A variety of reasons for not 
participating in the program were mentioned by the interviewees. Women who felt they were overweight, disfigured or in some other way had negative feelings about their bodies were more likely to not participate in the program because of the embarrassment of being naked in front of another person.

It was not that the tester would have a negative impression about how I looked naked, it was my own insecurity about my body that was the issue.

Daily tasks and family situations often discouraged women from showing up for their appointments. Children related issues, work situations in general and other health related issues were cited among the interviewees as being reasons for their missing appointments. The waiting period between the test and the results was too long for some women so they decided to not participate on these grounds. Some women that were not sexually active felt that they embarrassed to admit to that or they felt that it was not required of them to take the test.

\section{Discussion}

The domain of the study can be described as how women's past experiences in general affect their decision making process about whether or not to respond to the Pap smear notification. Through the interview process it was demonstrated by the responses that the issues could be categorized into three basic categories. The categories were identified as communication, treatment and subterfuge (reasons or excuses for not participating).

The communication issues that the interviewees had with the notification process are clearly issues that potentially can be resolved. The notification that was delivered to the women was lacking in specific details about what the Pap smear test actually was and how it was performed. This lack of detailed information was often perceived as a factor that influenced women not to respond to the screening and testing. For example, a large contributing reason for cell changes that the Pap smear test detects is the Human Papilloma virus which is transmitted with sexual activity [7] and this is information that is relevant to the women who are receiving the notification. A technical explanation about what exactly the procedure is and how it is done is also clearly relevant to the women. It is important that the women have at least a working knowledge about the procedure so that they can feel comfortable enough with the caregiver in order that the test can be done without unnecessary discomfort [15].

When women respond to the Pap smear screening and testing program they often would like to use the session to discuss other questions regarding their sexual behavior, their reproductive health and menopause. This finding in the study was confirmed by the Bloomberg study cited in the above paragraph and also in another earlier study [8]. Proper and comprehensive answers to the women's ques- tions which reflect their diverse need for information is another factor that could encourage women to respond to the screening and testing in the future.

Past or previous gynecology procedures or operations may effectively exempt certain women from requiring a Pap smear test. Testing criteria for each potential participant in the Pap smear screening and testing program should carefully match each woman and identify her accurately as a candidate for the program. Other problems in the communication category included difficulty in telephone contacts. Women calling looking for information or to change appointment times were unable to make contact and this was enough reason for them to not respond to the notification.

Treatment issues among the interviewees generally fell into several different areas of concern. Some of the women mentioned the prevalence of red tape within the system as being a factor in their lack of response. Others concerns were apparently from past experiences in the healthcare system that may have been of positive or negative nature and sometimes the fear of a repetition of a negative experience was a discouraging factor in responding to the notification for the Pap smear program. Interviewees cited instances of lack of attentive listening to their issues or problems which may have contributed to a lack of resolution to an ongoing issue. They want treated with dignity and respect $[16,17]$.

The ambience of the treatment facilities is important for the women's perception of the testing experience and can have an influence on their decision to respond to the notification or not. The treatment room should have an organization within itself that allows the women to feel that her privacy is respected from the time she enters the facility until the time that she leaves. Since the testing requires the women to undress, sit in the examination chair and then get dressed again she is going to feel "naked” during the appointment and her feelings and fears must be addressed in the layout of the room itself. A discrete dressing facility, providing a proper dressing gown and a private testing position must all be addressed with regard to her feelings and need for security.

There were cases of insensitive physical contact between the caregiver and the patient where the patient felt that the touch was too hard or inappropriate. These factors within the care giving system emphasize how important it is that the caregiver is sensitive and sympathetic to women in delicate treatment situations that make them emotionally and physically vulnerable $[9,10]$. The personnel that are directly involved in the Pap smear testing must be aware of the women's fears and potential anxiety about the testing situation [18].

The women's experiences and past sexual history often had a bearing on whether or not they responded or not to the Pap smear notice. In cases where there had 
been experiences of physical or mental abuse, violence of a sexual nature or even violations in the trust between the caregiver and the patient, there already existed a tendency to not want to participate in any testing that involved their reproductive systems. In these cases of abuse or violation the women generally had a more difficult time maintaining a good sense of self-esteem and were more prone to feeling traumatized by gynecology examinations of any nature $[9,19]$.

There are other extenuating circumstances that prevent women from responding to the notice for a Pap smear test. The most common issues in this category with the interviewees fall under the subject about how they perceive themselves in a situation where they are forced to be naked in front of someone else. Their concerns are more about themselves than how the caregiver might perceive them. Being overweight or perhaps having some sort of disfigurement was a factor in women not responding to the notice. Women in today's world are often overextended because they are working full time jobs and at the same time trying to manage their families and children. Because of this their own health may be a lower priority than their everyday concerns.

One interesting finding of this study was that the women who were interviewed maintained that they were more likely to show for their mammography examination than their Pap smear test. From their point of view the women perceived that the test for breast cancer was less embarrassing than the screening for the cervical cancer [15]. Another finding in the study revealed that women who felt that they were in very good health did not respond to the notification because they felt it was unnecessary [20, 21].

\section{Conclusion}

Judging from the responses of the interviewees, the major issues that women have that prevent and discourage them from showing up for the Pap smear screening and testing is the issue of trust because of the sensitivity of the test and the results. A trusting relationship can more effectively be nurtured if some of the administrative routines are changed or modified to accommodate the women's need for privacy and understanding. The personnel administering the actual test have an enormous bearing and responsibility regarding the trust issues that the women have and how the women feel about the Pap smear screening and testing procedure itself. The midwife that performs the actual test must be aware that each woman is in the continuum of illness and health and be skillful in coaching and enabling each woman to their individual status in this regard. Since the Pap smear test reduces the risk for cervical cancer it is imperative that women feel a sense of trust and wellbeing with regard to the healthcare system in order to increase and improve the participation in the program.

\section{Acknowledgements}

The authors are grateful to all of the women who participated in the study and shared their emotional experience.

\section{REFERENCES}

[1] The National Board of Health and Welfare [Socialstyrelsen], "Special Conditions in Health Care [Speciella Förhållanden I Hälsooch Sjukvården],” 2002, pp. 106-116.

[2] The National Board of Health and Welfare [Socialstyrelsen], "Cancer of the Figures Expository Facts about Cancer [Cancer i Siffror Populärvetenskapliga Fakta om Cancer]," 2009.

http://www.cancerfonden.se/Global/Dokument/omcancer/ cancer_i_siffror/Cancer_i_siffror_2009.pdf

[3] P. Bistoletti and K. Sennfält, “A Health Economic Model Study of Primary Screening for Cervical Cancer with Pap Smear and HPV DNA Testing, [En Hälsoekonomisk Modellstudie av Primärscreening Mot Livmoderhalscancer Med Cellprov och HPV DNA-Test],” CMT Rapport, Vol. 1, Linköping University, Linköping, 2008.

[4] C. Crum, "Should the Bethesda System Terminology be Used in Diagnostic Surgical Pathology?” International Journal of Gynecological Pathology, Vol. 22, No. 1, 2002, pp. 5-12. doi:10.1097/00004347-200301000-00003

[5] B. Strander, A. Andersson-Ellström, I. Milsom, T. Rådberg and W. Ryd, "Liquid-Based Cytology versus Conventional Papanicolaou Smear in an Organized Screening Program,” Cancer, Vol. 111, No. 5, 2007, pp. 285-291. doi:10.1002/cncr.22953

[6] B. Andrae, L. Kemetli, P. Sparén, L. Silfverdal, B. Strander, W. Ryd, J. Dillner and S. Törnberg, "Screening-Preventable Cervical Cancer Risks: Evidence from a Nationwide Audit in Sweden,” Journal National Cancer Institute, Vol. 100, No. 9, 2008, pp. 622-629.

[7] J. Dillner, "Screening-Preventable Cervical Cancer Risks: Evidence from Nationwide Audit in Sweden," Journal of the National Cancer Institute, Vol. 100, No. 9, 2008, pp. 622-629.

http://ki.se/ki/jsp/polopoly.jsp;jsessionid=azpVBpLnE0M dTbZoO4?l=sv\&d=6203\&a=55868\&newsdep=6203

[8] M. G. Oscarsson, B. E. Wijma and E. G. Benzein, "Nonattendance in a Cervical Cancer Screening Program-What Happens if Women's Requirements Are Met?” Health Care for Women International, Vol. 29, No. 2, 2008, pp. 183-197. doi:10.1080/07399330701738242

[9] B. Wijma and K. Siwe, "The Empowerment Gyn Chair, Theory. Empirical and Opportunities. [Empowerment i Gynstolen. Teori. Empiri och Möjligheter],” Women's Scholarly Journals, Vol. 2-3, 2002, pp. 61-73.

[10] B. Wijma, "Prevalence of Emotional, Physical, and Sexual Abuse. A Nordic, Cross-Sectional, Multicentre Study among Patients Visiting Gynaecological Clinics,” Linköping University, Linköping, 2003.

[11] K. Eriksson, “Health Hibernation, [Hälsans Ide],” Almqvist och Wiksell, Stockholm, 1993. 
[12] A. Antonovsky, "Health Mystery, [Hälsans Mysterium]," Natur och Kultur, Stockholm, 1991.

[13] S. Kvale, "The Qualitative Research Interview, [Den Kvalitativa Forskningsintervjun],” Studentlitteratur, Lund, 1997.

[14] U. H. Graneheim and B. Lundman, "Qualitative Content Analysis in Nursing Research: Concepts, Procedures and Measures to Achieve Trustworthines," Nurse Education Today, Vol. 24, No. 2, 2004, pp. 105-112. doi:10.1016/j.nedt.2003.10.001

[15] K. Blomberg, "From Invitations to Follow Women's Experiences of Participating or Not Participating in Cervical Cancer Screening. [Från Inbjudan till Uppföljning Kvinnors Erfarenheter av att Delta Eller inte Delta i Cervixcancerscreening],” Universitet Service US-AB, Stockholm, 2009.

[16] M. Oscarsson, B. Wijma and E. Benzein, “'I Do Not Need to...I Do Not Want to...I Do Not Give it Priority...'-Why Women Choose not to Attend Cervical Cancer Screening,” Health Expectations, Vol. 11, No. 1, 2007, pp. 2634. doi:10.1111/j.1369-7625.2007.00478.x
[17] M. Ideström, I. Milsom and A. Andersson-Ellström, "Knowledge and Attitudes about the Pap Smear Screening Program: A Population-Based Study of Women Aged 20-59 Years," Acta Obstetricia et Gynecologica Scandinavica, Vol. 81, No. 10, 2002, pp. 962-967.

[18] K. Dahlberg, "Health Suffering-The Needless Suffering, [Vårdlidande-Det Onödiga Lidandet]," Vård I Norden, Vol. 22, No. 1, 2002, pp. 4-8.

[19] K. Swahnberg, "Prevalence of Gender Violence. Studies of Four Kinds of Abuse in Five Nordic Countries," Doctoral Dissertation, Akademitryck AB, Edsbruk, 2003.

[20] S. Eaker, “Optimization of Compliance in Epidemiologic Research and Diseasemprevention. With Special Emphasis on Pap Smear Screening," Doctoral Dissertation, Karolinska Institute, Stockholm, 2003.

[21] S. Eaker, H.-P. Adami and P. Sparén, "Reasons Why Women Do Not Attend Screening for Cervical Cancer; a Population-Based Study in Sweden," Preventive Medicine, Vol. 32, No. 6, 2001, pp. 482-491.

doi:10.1006/pmed.2001.0844 